\title{
Determinants of Risk Management Adoption in Organisations and Supply Chains
}

\author{
NORLAILE Salleh Hudin ${ }^{1,}$, ABU BAKAR Abdul Hamid²,b THOO Ai Chin ${ }^{3, c}$ \\ ${ }^{1}$ Universiti Pendidikan Sultan Idris, Malaysia \\ ${ }^{2}$ International Business School, Universiti Teknologi Malaysia, Malaysia \\ ${ }^{3}$ Universiti Teknologi Malaysia, Malaysia \\ alaile_sh@yahoo.com, ${ }^{b}$ m-abakar@utm.my, ${ }^{c}$ acthoo@utm.my
}

Keywords: Risk management adoption, determinants, perception of risk management, risk perception.

\begin{abstract}
The implementation of risk management (RM) increases the value of firms, reduces the cost of debts, increases profits and improves decision making. However, the debates on what determines RM adoption are still unresolved due to limited evidence of RM adoption in industrial settings. Therefore, this paper aims to propose a conceptual framework of the determinants that influence the adoption of RM. It has been found that two factors, the perception of risk management and risk perception, have often been neglected in prior research. Thus, this paper extends the existing literature by introducing these factors to the framework of RM adoption. It is suggested that future case studies can be conducted to examine the significance of these two factors.
\end{abstract}

\section{Introduction}

This century has witnessed the emergence of an abundance of risks from outsourcing activities and occurrence of force majuere events. Recognising this problem, scholars and industrial practitioners have paid more attention on risk management (RM) [1]. RM is a process of predicting the potential risks that can occur in an organisation and coming up with suitable strategies to limit the consequences of these risks [2]. It provides more systematic decision making, reduces cost and increases supply chain performance. Despite the growing interest in RM, RM adoption or implementation seems to be scarced [3],[4]. Thus, with the purpose of advocating RM as common practices in companies, it is necessary to understand the determinants that encourage the adoption of this new organisational development. Therefore, this paper attempts to answer the question, "What factors stimulate the adoption of RM in companies?" The final aim is to provide a conceptual framework that links the determinants of RM adoption to the actual adoption of RM. The main contribution of this study is the introduction of another two new determinants of RM adoption: the perception of RM and risk perception, as well as the introduction of diffusion of innovation theory (DOI) and relational theory of risk to explain the phenomenon. To verify the framework, case studies are suggested to be conducted where data are collected through interviews and triangulated by observation and document analysis. The data could then be analyzed by using thematic analysis which involves transcribing the interviews, coding and categorizing the data and interpreting the information.

\section{Literature Review}

Past studies revealed inconclusive evidences concerning the determinants of RM adoption and implementation as summarized in Table 1. Financial leverage was found to be a significant determinant 
of RM adoption [3] but another study found the opposite [7]. Moreover, while firm size was proven to be significant determinant of RM [11], it was insignificant in a more recent study [7].

Table 1: Summary of determinants of RM adoption

\begin{tabular}{|c|c|c|c|c|c|c|c|c|c|c|}
\hline \multirow{2}{*}{ Determinants } & \multicolumn{10}{|c|}{ Reference(s) } \\
\hline & {$[3]$} & {$[4]$} & {$[5]$} & {$[6]$} & {$[7]$} & {$[8]$} & [9] & {$[10]$} & {$[11]$} & {$[12]$} \\
\hline $\begin{array}{l}\text { Presence of Chief Risk } \\
\text { Officer and internal auditor }\end{array}$ & & & I & & / & & & / & / & / \\
\hline Top management support & & & / & & & & & & / & \\
\hline Board of Directors support & & & / & & & & & & & \\
\hline Type of firm/industry & & & / & / & & & & / & / & \\
\hline Company turnover & & & / & & / & & & & & / \\
\hline Company size & & & / & / & & / & & / & / & / \\
\hline Corporate governance & & & / & & & & & & & \\
\hline Compliance with regulations & & & / & & & & & & & \\
\hline Pressure from auditors & & & & & & & & & / & \\
\hline Technology advancements & & / & & & & & & & & \\
\hline Competitive advantage & & / & & & & & & & & \\
\hline Corporate companies' failures & & / & & & & & & & & \\
\hline Good business practice & & / & & & & & & & & \\
\hline Complexity of risks & & / & & & & & & & & \\
\hline $\begin{array}{l}\text { Majority of shareholder } \\
\text { requirements }\end{array}$ & & / & & & & & & & & / \\
\hline Globalisation & & / & & & & & & & & \\
\hline Improved communication & & / & & & & & & & & \\
\hline Financial leverage & / & & & & & & / & & & / \\
\hline Type of auditor & / & & & / & & & & & & \\
\hline Firm complexity & & & & / & / & & & & & / \\
\hline Country of domicile & & & & / & & & & & & \\
\hline $\begin{array}{l}\text { Independence of Board of } \\
\text { Directors }\end{array}$ & & & & / & & & & & l & \\
\hline Volatile cash flow & & & & & & / & & & & \\
\hline Riskier stock return & & & & & & / & & & & \\
\hline $\begin{array}{l}\text { Presence of auditor } \\
\text { committee }\end{array}$ & & & & & & & & l & & \\
\hline Profitability & & & & & & & & & & / \\
\hline
\end{tabular}

The summary of the determinants of RM adoption leads to the conclusion that the execution of RM is dependent upon many factors, which have yet to be agreed upon by researchers. However, the effects of perception towards RM and risk perception, have received less attention from scholars. Thus, the next subsection discusses the argument that these factors have had an impact on RM adoption.

Perception of Risk Management. As RM is not compulsory in some industries, it is interesting to explore why firms in such industries decided to adopt RM practices. One of the possible explanations is that the adoption of enterprise RM depends on people's perception of RM [13] which can be negative or positive ones. Among those with a positive perception, recognition of RM's potential benefits had been found to stimulate its adoption [10]. A study reported that most respondents were convinced of the benefits of RM and unlike the banking and insurance industries which have rigid RM regulations, companies in the oil and gas industry adopted RM for its value-creating opportunity and considered it a 
good business practice [14]. Moreover, companies adopted RM mainly due to economic benefits rather than pressure from regulatory bodies [8]. In stark contrast, a negative perception of RM among managers and employees can hinder its adoption. Managers stated that "nobody gets credit for solving problems that did not happen" [15] whereas employees perceived RM as yet another new method in their work routine [16]. Therefore positive perceptions of RM result in the adoption of RM, whereas negative perceptions hinder its application.

Risk Perception. The perception of increasing risk occurrence is causing growing demand for RM. For example, RM is often associated with well-known risk events such as the 9/11 terrorist attack, Hurricane Katrina and the outbreak of SARS. These events received global media coverage which increased people's perception of risk. In supply chain, risk perception can also increased by many factors such as the interruption of supplies or routine report from suppliers. Thus, the increasing risk perception triggers individuals into taking protective action [20]. For the purpose of this paper, protective action implies to the adoption of RM. The owners of small and medium enterprises (SMEs) also have a higher level of risk perception compared to their larger counterparts [21] due to stringent financial support and difficulty to obtain loan from banks. Earlier studies have proven that RM turned out to be an essential interest of SMEs particularly with regards to their tendency to become insolvent [22]. This indicates that the awareness of the vulnerabilities inherent in SMEs could logically inspire the adoption of RM.

\section{Proposed Conceptual Framework}

The current paper proposes a framework that comprises two commonly neglected factors of RM adoption: the perception of RM and risk perception as shown in Fig. 1. This framework is grounded within the diffusion of innovation theory (DOI) and the relational theory of risk which are explained in the next section. The first factor, the perception of risk management, consists of the perceived advantages of RM, RM compatibility with existing business operations, complexity of RM implementation, triability of RM practice and observability of RM benefits as proposed in DOI. Additionally, risk perception, as theorised by the relational theory of risk, consists of the perceived importance of 21 drivers of risk [1]. RM adoption comprises the availability of standard RM processes, attitudes towards risk, tools used in RM processes, techniques used to minimise risk, risk communication, RM training and risk responsibilities [22],[23].

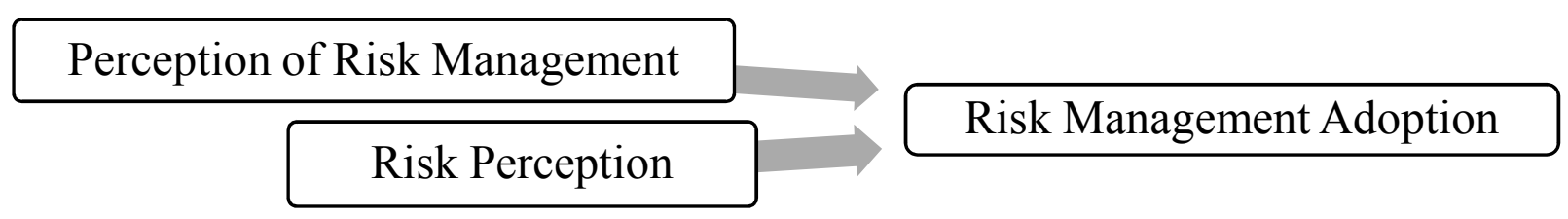

Figure 1: Proposed conceptual framework.

\section{Theories}

The conceptual framework above is grounded within the DOI and relational theory of risk. With respect to the DOI, innovation is defined as "an idea, practice or object" [25] which in this study refer to the risk management practices. The innovation-decision is determined by five key aspects: (1) the relative advantage, (2) compatibility, (3) complexity, (4) triability and (5) observability of an innovation which have a positive relationship with the innovation adoption decision except for the 
complexity aspect. With regard to this premise, the five key aspects of innovation-decision measured based on perception, is embedded in the conceptual framework to represent the perception of RM.

On the other hands, the relational theory of risk explains that understanding the risk from several perspectives is therefore the springboard to decision and action with respect to RM [26]. For the purpose of this study, the understanding of how managers perceived the importance of 21 drivers of risk [1] determines how they implement RM. If managers perceived most of the risks as important, they are most probably implementing more formal RM and preparing more risk minimising strategies than those managers who perceived that most of the risks as non-threatening.

\section{Conclusion}

The identification, classification, analysis and effective reaction to risks determine the success of an organisation [5]. Nevertheless, there is scant evidence of RM adoption in organisations [3],[4]. As a result, this paper seeks to bridge this gap by investigating the determinants of RM adoption. The review of the literature outlines a number of factors that influence RM adoption, but to the best of knowledge, none has introduces the perception of risk management and risk perception. Therefore, this paper proposes a conceptual framework of RM adoption that links the perception of risk management and risk perception to RM adoption. Case studies to investigate the effects of the perception of RM and risk perception on RM adoption are highly encouraged to enrich the body of RM knowledge.

\section{References}

[1] G. A. Zsidisin, S. M. Wagner, S. A. Melnyk, G. L. Ragatz, L. A. Burns, Supply risk perceptions and practices: An exploratory comparison of German and US supply management professionals, Int. J. of Technology, Policy \& Management. 8, 4 (2008) 401-419.

[2] Committee of Sponsoring Organizations of the Treadway Commission, Enterprise Risk Management: Integrated Framework, American Institute of CPA, Jersey City, 2004.

[3] N. M. Golshan, S. Z. Rashid, Determinants of enterprise risk management adoption: An empirical analysis of Malaysian public listed firms, Int. J. of Social \& Human Sciences. 6 (2012) 119-126.

[4] N. A. Manab, I. Kassim, M. R. Hussin, Enterprise-wide risk management (EWRM) practices: Between corporate governance compliance and value creation, Int. Review of Business Research Papers. 6, 2 (2010) 239-252.

[5] N. A. M. Abdullah, N. Zakuan, M. Khayon, M. S. M. Ariff, N. E. N. Bazin, M. Z. M. Saman, Adoption of enterprise risk management practices in organization: A Review, Int. J. of Business \& Information Technology. 2, 1 (2012) 1-9.

[6] N. M. Golshan, S. Z. Rasid, What leads firms to enterprise risk management adoption? A literature review, Int. Conference on Economics, Business \& Marketing Management, Singapore, IACSIT Press (2012a) 276-280.

[7] A. R. Razali, A. S. Yazid, I. M. Tahir, The determinants of enterprise risk management (ERM) practices in Malaysian public listed companies, J. of Social \& Development Sciences. 1, 5 (2011) 202207.

[8] D. Pagach, R. Warr, The characteristics of firms that hire chief risk officers, The Journal of Risk \& Insurance. 78, 1 (2011) 185-211. 
[9] A. P. Liebenberg, R. E. Hoyt, The determinants of enterprise risk management: Evidence from the appointment of chief risk officers, Risk Management \& Insurance Review. 6, 1 (2003) 37-52.

[10] L. Paape, R. F. Spekle, The adoption and design of enterprise risk management practices: An empirical study, European Accounting Review. 21, 3 (2012) 533-564.

[11] M. S. Beasley, R. Clune, D. R. Hermanson, Enterprise risk management: An empirical analysis of factors associated with the extent of implementation, J. of Accounting \& Public Policy. 24 (2005) 521531.

[12] A. S. Yazid, A. R. Razali, M. R. Husin, Determinants of enterprise risk management (ERM): A proposed framework for Malaysian public listed companies, Int. Business Research. 5, 1 (2012) 80-86.

[13] S. A. Malik, B. Holt, Factors that affect the adoption of enterprise risk management (ERM), OR Insight. 26 (2013) 253-269.

[14] K. Muralidhar, Enterprise risk management in the Middle East oil industry: An empirical investigation across GCC countries, Int. J. of Energy Sector Management. 4, 1 (2010) 59-86.

[15] J. B. Rice Jr., F. Caniato, Building a secure and resilient supply network, Supply Chain Management Review. 7, 5 (2003) 22-30.

[16] B. Freimut, S. Hartkopf, P. Kaiser, J. Kontio, W. Kobitzsch, An industrial case study of implementing software risk management. proceeding, 8th European Software Engineering Conference, Vienna, Austria, ACM (2001) 277-287.

[17] K. E. Stecke, S. Kumar, Sources of supply chain disruptions, factors that breed vulnerability, and mitigating strategies, J. of Marketing Channels. 16 (2009) 193-226.

[18] D. Kern, R. Moser, E. Hartmann, M. Moder, Supply risk management: Model development and empirical analysis, Int. J. of Physical Distribution \& Logistics Management. 42, 1 (2012) 60-82.

[19] A. A. Wahlberg, L. Sjoberg, Risk perception and the media, J. of Risk Research. 3, 1 (2000) 3150 .

[20] T. Cooper, A. Faseruk, Strategic risk, risk perception and risk behaviour: Meta-analysis, J. of Financial Management \& Analysis. 24, 2 (2011) 10-11.

[21] C. Ellegaard, Supply risk management in a small company perspective, Supply Chain Management: An International Journal. 13, 6 (2008) 425-434.

[22] T. Henschel, Risk Management Practice of SMEs: Evaluating and Implementing Effective Risk Management Systems, Erich Schmidt Verlag GmbH \& Co, Berlin, 2008.

[23] O. Lavastre, A. Gunasekaran, A. Spalanzani, Supply chain risk management in French companies, Decision Support Systems. 52 (2012) 828-838.

[24] M. F. Blos, M. Quaddus, H. M. Wee, K. Watanabe, Supply chain risk management (SCRM): A case study on the automotive and electronic industries in Brazil, Supply Chain Management: An International Journal. 14, 4 (2009) 247-252.

[25] E. M. Rogers, Diffusion of Innovations, 4th ed., The Free Press, New York, 1995.

[26] Å. Boholm, H. Corvellec, A relational theory of risk, J. of Risk Research. 14, 2 (2011) 175-190. 